\title{
$\begin{array}{ll}\text { Research Square } & \text { Preprints are preliminary reports that have not undergone peer review. } \\ \text { They should not be considered conclusive, used to inform clinical practice, }\end{array}$ or referenced by the media as validated information. \\ Digital Media Technology Application Research Based on $5 \mathrm{~g}$ Internet of Things Virtual Reality Technology as the Carrier
}

\section{Xingchen Zhang}

Shandong Technology and Business University

zaiyi pu ( $\square$ zaiyipu@cwnu.edu.cn )

China West Normal University

\section{Xinbo Jiang}

Shandong Technology and Business University

\section{Research Article}

Keywords: Internet of Things, Virtual Reality, Three-Dimensional Model, Digital Media

Posted Date: March 15th, 2021

DOI: https://doi.org/10.21203/rs.3.rs-298090/v1

License: (c) This work is licensed under a Creative Commons Attribution 4.0 International License.

Read Full License 


\title{
Digital Media Technology Application Research Based on 5g Internet of Things Virtual Reality Technology as the Carrier
}

\author{
Xingchen Zhang ${ }^{1, \mathbf{a}}$ Zaiyi $\mathbf{P u}^{2, b^{*}}$ and Xinbo Jiang ${ }^{1, \mathrm{c}}$ \\ ${ }^{1}$ School of Computer Sicence and Technology, Shandong Technology and Business University, \\ Yantai 264003, Shandong, China \\ ${ }^{2}$ Education and Information Technology Center, China West Normal University, Nanchong \\ 637009, Sichuan, China \\ a201613590@sdtbu.edu.cn \\ baiyipu@cwnu.edu.cn \\ cxinboj@gmail.com \\ ${ }^{*}$ Corresponding author
}

\begin{abstract}
With the development of the 5G era, digital media technology has been widely used in many fields and industries. Virtual reality is the product of the application of digital media technology in the development process. At the level of the continuous development and progress of social science and technology, virtual reality technology as a high-tech and high-tech tool has gradually entered people's vision, penetrated into all aspects of people's lives, and exerted good results. This article mainly studies the application of digital media technology based on 5G Internet of Things virtual reality technology as the carrier. This article introduces virtual reality technology, Quick Time VR technology that can be used in digital media, Tilt Brush VR technology, Oculus Quill technology, and digital media technology. It builds a virtual reality-based 3D model and digital media Internet of Things architecture, and implements 5G Comparison of technology and traditional technology, the proportion of applications of 5G Internet of Things virtual reality technology and digital media technology in education, construction, industry and medical fields. The analysis results show that the $5 \mathrm{G}$ Internet of Things has higher visual immersion, the original bandwidth can reach $5 \mathrm{Tbit} / \mathrm{s}$, and the calculation time of a single hologram is less than 3ms; $5 \mathrm{G}$ technology and virtual reality technology are both used in the medical field the most, with applications accounting for up to $40 \%$; Digital media technology is the most widely used in the construction field, reaching $60 \%$. It can be seen from the research in this article that the application of digital media technology based on the virtual reality technology of $5 \mathrm{G}$ Internet of Things as the carrier has high practical value in reality.
\end{abstract}

Keywords: Internet of Things, Virtual Reality, Three-Dimensional Model, Digital Media

\section{Introduce}

Virtual reality technology is a new type of technology that includes computers, electronic information, and simulation technology. To realize virtual reality technology, the first step is to create a virtual environment through a computer so that people can feel the existence of the virtual environment. During the development and progress of social productivity and science and technology, the demand for virtual reality technology in various fields of life including digital media technology is also increasing. Virtual reality technology has made considerable progress and has gradually become a new field of science and technology.

The development of digital technology is smoother than actual technology. If virtual reality 
technology is applied to digital media technology, the creative expression of digital media will be more natural. At the same time, the interaction between people is more perceptual and personalized, which greatly improves the charm and expressiveness of the virtual reality environment. Therefore, in the development of this new era, please use it to develop digital media. From a practical point of view, electronic technology has important interactions.

Bastug E just recently, the concept of augmented virtual reality (AR/VR) based on wireless technology has swept the entire 5G ecosystem, arousing unprecedented interest in academia, industry and others. However, the success of an immersive virtual reality experience depends on solving a large number of major challenges across multiple disciplines. He emphasized the importance of virtual reality technology as a disruptive use case for 5G (and above), which utilizes the latest developments in storage/memory, fog/edge computing, computer vision, artificial intelligence and other fields. In particular, it describes the main requirements of wireless interconnected virtual reality, and then selects some key enabling technologies; then introduces the research approach and its potential major challenges. In addition, they reviewed three virtual reality case studies and provided numerical results under different storage, computing, and network configurations. Finally, he revealed the limitations of the existing network, and put forward more theories and innovative reasons to provide the public with a pioneer in virtual reality. However, there are still huge challenges in the research approach [1]. Vera L proposed that virtual reality immersion (VRI) is an advanced computer-generated technology that reduces the subjective report of pain in experimental and procedural medical treatments. In addition, as measured by functional magnetic resonance imaging, VRI significantly reduces pain-related brain activity. The similarities between the anatomy of pain and itch and the neuroendocrine pathways may prove that VRI is an adjunct to basic and clinical research on complex aspects of itch. He compared the vulgar effects of VRI and audiovisual traction (AVD) technology in reducing itching in patients with atopic dermatitis and psoriasis. 24 patients with chronic itching, 16 of them with atopic dermatitis and 8 with psoriasis vulgaris, were randomly assigned to an interactive computer game using a special mask or computer screen. Before exposure, during exposure, and within 10 minutes after exposure, self-assess the intensity of itching using a visual analog scale (0-10). The interviewer rated the observed scratches at level 3. However, the experimental effect is not ideal [2]. Lee FLF Although digital media is widely regarded as a predictor of protest participation and a platform for coordinating related actions, few studies have explored how digital media activities are systematically related to the way protesters participate in protests. His research aims to fill in the research gaps by analyzing the Hong Kong umbrella movement. It determines the time in the occupied area, participation in leadership, and the form of action taken, as three aspects of the protesters' participation methods, which can indicate the protesters' participation in the movement. Analysis of on-site investigations of protesters shows that protesters are active in four digital media activities: online expressions, online debates, online commentary activities, and mobile communications. Digital media activities are generally positively correlated with the degree of participation, but these four types of activities also have different connections to the three aspects of participation. However, his research lacks the analysis of human subjective and objective factors [3].

The innovations of this article: (1) Combining qualitative research and quantitative research, fully combining research data with practical application value, and showing the practical value of this research; (2) Combining theoretical research and empirical research, in deep learning virtual 
Based on the theoretical basis of real technology and digital media technology, empirical investigations in various fields are combined.

\section{Digital Media Technology Application Research Methods Based on 5g Internet of Things}

\section{Virtual Reality Technology as the Carrier}

\subsection{Overview of Virtual Reality Technology}

(1) Features of virtual reality technology

Through scientific virtual experience, a variety of real environments are created. Users use specific input and output devices to interact with the virtual world [4]. Virtual reality technology has the following characteristics: 1) Immersion. Immersiveness refers to the user's degree of involvement or sense of substitution in the virtual space. Immersion can be divided into semiimmersion and full immersion. The biggest difference is the degree of immersion. The same point is that they all need the help of external devices to complete the immersive experience. 2) Interactivity. People can quickly accept the market promotion of virtual technology. What matters is interaction. The technical feature is that it can communicate with people and form communication and dialogue. Make actual scenes, talk to people in the same actual scene, influence people's actions, and let users feel the actual conversation. 3) Imagination. Virtual reality technology provides designers and users with a better game space, and better realizes people's imagination of the future world, the unknown world, and the ideal world [5-6].

(2) The relationship between virtual reality technology and digital media technology

According to existing survey data, it has not been more than 30 years since the development of virtual reality technology, but people's enthusiasm for it has been rising all the way, and more and more people are paying attention and participating in it. Digital media technology is closely related to virtual reality. In other words, digital media technology is the foundation of virtual reality. This technology is mainly composed of two parts: post-processing design and scene design, and its scope is also very wide, which can transform abstract content into concrete content that adults can perceive. For example: applying this technology to the production of mobile projects can turn project pages into comics, supplement virtual reality technology, and let ordinary people feel you on the stage. In other words, the advantages of these two special properties are combined. Only two or more digital technologies can be separated from the virtual.

Multimedia technology provides corresponding technical conditions for virtual reality. Multimedia technology includes post-stage design and processing [7]. Multimedia technology can extensively process text, sound, graphics, images and other information through the latest computing and communication methods in order to identify abstract information. Interaction technologies that can be used mutually. Figure 1 shows the correlation between virtual reality technology and digital media technology. 


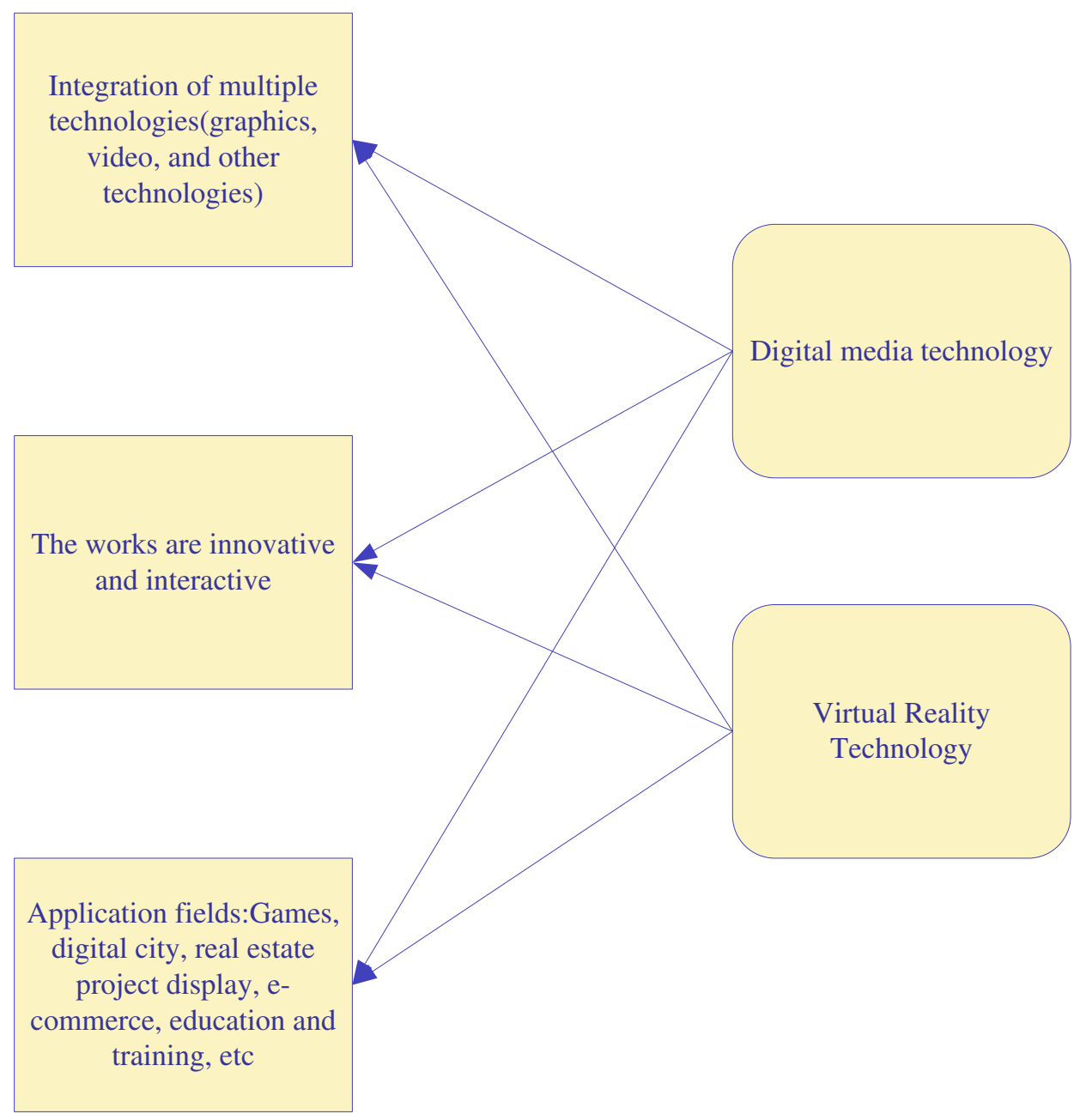

Figure 1. The relevance of virtual reality technology and digital media technology

\subsection{Quick Time VR Technology}

High-speed virtual reality technology is very popular in current virtual reality technology families and is a widely used technology. Quick-Time-VR (Quick-Time-VR) is mainly a virtual reality technology based on still images applied to a microcomputer platform [8]. Not only panoramic observation and 3D graphic image display, but also 360-degree viewing and experiencing 3D virtual space on a flat observation platform. Bring a stimulating experience of the environment. At the same time, high-speed virtual reality technology not only provides a good experience for the aesthetics of three-dimensional objects and spaces, but also a good experience for the audience. At the same time, it also has convenient and excellent processing functions. New media using virtual reality technology are more interactive with participants [9]. You can copy content to the playback process. In addition, Quick Time VR technology does not require high equipment, and viewers can edit flat photos smoothly. Color adjustment, restoration and various operation settings are usually realized functions. Very unique. The important thing is that many photos can be linked to 3D graphics. The audience can see the content of the image more clearly. By connecting the image content, the image content can be expressed smoothly. He not only has the ability to perceive images, but also brings the audience. Think of more useful words. From this point of view, Quick Time VR technology can make a simple person a popular director in the United States and realize his dream.

Thanks to the emergence of Quick Time VR technology, AgOg digital media has become more 
convenient and free. Professional art majors can not only produce more kinds of materials based on existing materials, but also provide a better platform for artists. Virtual reality technology has a wide range of uses in real life. On the other hand, it has convenient processing functions and excellent extension functions [10]. It can be observed from all angles of the graph, and the reproduction speed and observation scene can be freely selected. On the other hand, the price of high-speed virtual reality technology is low, and the space of IN-9 is widely popularized and generally accepted [11].

\subsection{Tilt Brush VR Technology}

Virtual reality technology provides a more flexible and creative method for traditional painting. With the development and progress of virtual reality technology, many artists began to use the concept of virtual space to make. Can create a virtual space and software. The previous art works and paper and pen are combined in the form of electronic projects, and creators can directly use virtual reality technology tools [12]. The pitch brush is a virtual space item. 3D imaging applications using tools such as headsets, eye masks, handheld devices, etc. The application provides different styles of 3D space for painting, including space, which is a bit similar to the skin in Paper; it also provides a variety of styles of brushes, such as rainbows, glowing bands, stars, smoke, and even maple leaves. It is also said that through the movement of portable machines, creators can express themselves smoothly, which is a creative method of space travel. Creators can make in virtual space and evaluate their own works in virtual space. Innovative creative methods can not only create more flexible content, but also give creators a better sense of participation and experience. This kind of painting made with tilted brush VR was also collected from the world's first virtual reality art exhibition held by Google in San Francisco. This technology brings more creative possibilities through the production of mobile projects, improves the realization of the production of characters and scenes, and increases production opportunities.

\subsection{Oculus Quill Technology}

Oculus Quill technology is an application tool of virtual reality in digital media, and art creators can make good use of this technology to create virtual spaces [13]. It is very similar to Tilt Brush technology. It is mainly composed of two parts: one is Oculus touch control, and the other is a sports camera [14]. Through these two combinations, creators can get unlimited possibilities. Like the function of TiltBrush, OculusQuill's palette and paint tools exist in a virtual space, and its simple operation characteristics make the famous VR animation "Angelika" and many other works of art come to life. Create an independent media with only its internal functions and functions.

\subsection{Digital Media Technology}

Digital media technology includes digital image processing technology, digital sound processing technology and computer processing technology [15]. Among them, digital imaging technology is the most basic technology of digital media technology. The technology includes digital media content, such as sampling, quantization, coding, etc. [16]. This kind of technical processing can compress a large amount of digital information. After the data conversion is completed, the compressed data information will be consolidated. The key of digital image processing technology lies in the input, recognition, output and output of digital signals [17].

Digital media image technology needs to specify the projection coordinates of each point of the virtual object in the actual environment image. This is an important link between real images and virtual images using augmented reality technology in the process of digital media optimization. The coordinate arbitrary point $[\mathrm{x} 0, \mathrm{y} 0, \mathrm{z} 0, \mathrm{w} 0]$ on the virtual environment or object in the threedimensional space and its coordinate mapping point $[\mathrm{u}, \mathrm{v}, \mathrm{h}]$ on the plane of the augmented reality 
system are represented in the form of homogeneous coordinates, The conversion equation between them can be expressed by the following (1):

$$
\left[\begin{array}{c}
u \\
v \\
h
\end{array}\right]=S_{3 * 4} B_{4 * 4} F_{4 * 4}\left[\begin{array}{c}
x_{0} \\
y_{0} \\
z_{0} \\
w_{0}
\end{array}\right]_{(1)}
$$

Among them, the mapping of the camera coordinate system to the two-dimensional imaging plane is represented by $\mathrm{S} 3 * 4$, the mapping of the real scene to the camera is represented by $\mathrm{B} 4 * 4$, and the transformation from virtual objects to the real environment is represented by $\mathrm{F} 4 * 4$.

In the concrete realization of digital media image optimization, the calibration and recording of each coordinate point in the three-dimensional space has a two-dimensional plane horizontal projection point [18]. In other words, the coordinates of the two positions correspond to one to one. Each corresponding point set is defined by two fixed equations. Each equation has 12 unknowns, $\mathrm{m} 11$ to $\mathrm{m} 34$. The equation is as follows:

$$
\begin{aligned}
& u_{1}=\frac{m_{11} X_{w i}+m_{12} Y_{w i}+m_{13} Z_{w i}+m_{14}}{m_{31} X_{w i}+m_{32} Y_{w i}+m_{33} Z_{w i}+m_{34}} \\
& v_{1}=\frac{m_{21} X_{w i}+m_{22} Y_{w i}+m_{23} Z_{w i}+m_{24}}{m_{31} X_{w i}+m_{32} Y_{w i}+m_{33} Z_{w i}+m_{34}}
\end{aligned}
$$

In the case of $2 \mathrm{i}$ equations, there are corresponding points $\mathrm{i}$, and $\mathrm{AM}==0$ can be defined. The parameter $A$ of this formula is a $12 * 2 \mathrm{i}$ matrix. For 12 unknown items, at least 6 corresponding points need to be known, and set $n \geq 6$. The result shows that if the error is small, the marked point needs to be selected further. The algorithm cannot receive accurate data. The calculation result is the minimum value of the possibility range, which is calculated based on the linear solution of the minimum AM.

\section{Experimental Model of Digital Media Technology Application Research Based on 5g}

\section{Internet of Things Virtual Reality Technology as the Carrier}

\subsection{Digital Media Technology Modeling Based on Virtual Reality Technology}

There are four modeling methods in virtual reality: geometric modeling, motion modeling, physical modeling, and action modeling [19]. There are two methods of geometric modeling: manual and automatic. The 4 non-automatic methods are as follows: 1 . Use opengljava $3 \mathrm{~d}, 2$ and other computer software for modeling. Purchase the required geometric shapes directly from the commodity library. Use AutoCAD, 3DMAX and other commonly used modeling software. 4. Automatic tool software. Use material equipment modeling, and sometimes use image-based geometric modeling methods. In the global coordinate system, the position and movement of objects on the virtual stage will be modeled by movement. You can adjust the movement through a virtual camera. There are two basic methods for virtual reality physical modeling: particle technology and fractal modeling. To move to the actual particle simulation, Fractal modeling usually uses simple 
functions to complete the modeling of complex objects, and is used for virtual reality modeling of static viewpoints [20-21].

In this article, we will learn the basic principles and applicable methods of 3D reconstruction technology based on 2D digital photos. The photo-based modeling process is as follows. (1) Take a picture with a camera, input the image modeling software to adjust the camera parameters, use various matching function groups, and find the internal and external start of the camera by using the image modeling software to combine the knowledge related to the verification of the camera parameters. parameter. (2) When deriving features based on the path method of latitude and longitude, when using image modeling software to determine feature points, it is best to choose points that can represent the spatial characteristics of the entity. The selected feature points help to finally form a three-dimensional solid model. (3) Use 3dsmax software to complete detailed model change operations. When using the $3 \mathrm{dsmmax}$ model to change the details, please repeatedly use multi-angle modeling, motion, zoom tools, etc. Change the detailed design drawing and complete the reconstruction of the model. (4) Finally, using large-scale 3D Pro/E design software, the surface modeling and curing work was completed [22]. After implementation, it can provide a threedimensional data model for subsequent rapid prototyping, and provide a suitable process path for the production of model samples and the display of related product samples.

The research of feature reconstruction algorithm has conducted experimental analysis on three feature linear reconstruction algorithms, nonlinear feature lateral method and least square method [23]. After the digital camera is calibrated, the global coordinate system has been established during calibration. For example, in the block, the three-dimensional coordinates of the reference point selected in the calibration area are identified in the global coordinate system. The coordinates of the $3 \mathrm{D}$ points calculated by the $3 \mathrm{D}$ point reconstruction algorithm are located in the global coordinate system. The evaluation index of error analysis is defined as: the absolute three-dimensional distance between the true value of the three-dimensional point in space and the reconstructed value $e_{i}$; the average absolute three-dimensional distance $\sigma$; the calculation formulas are as follows $\left(X_{i}, Y_{i}, Z_{i}\right)$ : actual world The coordinates are, and the world coordinates of the $3 \mathrm{D}$ reconstruction $\operatorname{are}\left(X_{i}^{\prime}, Y_{i}^{\prime}, Z_{i}^{\prime}\right):$

$$
\begin{array}{r}
e_{i}=\left(X_{i}-X_{i}^{\prime}\right)^{2}+\left(Y_{i}-Y_{i}^{\prime}\right)^{2}+\left(Z_{i}-Z_{i}^{\prime}\right)^{2} \\
\sigma=\sum_{i=1}^{N} e_{i} \\
e_{i}^{\prime}=\left(X_{i}-X_{i}^{\prime}\right)^{2}+\left(Y_{i}-Y_{i}^{\prime}\right)^{2}+\left(Z_{i}-Z_{i}^{\prime}\right)^{2} \\
X_{i}^{2}+Y_{i}^{2}+Z_{i}^{2}
\end{array}
$$




$$
\sigma^{\prime}=\sum_{i=1}^{N} e_{i}^{\prime}
$$

3.2 Digital Media Technology Architecture Model Based on $5 g$ Internet of Things Virtual Reality Technology as the Carrier

Combining the reusability and scalability of the IoT architecture, and according to the implementation requirements of digital media technology fully learned from the actual experience of virtual reality technology, a digital media system structure based on the virtual reality technology of the IoT5G model is proposed. The model is divided into five layers, including perception layer, transmission layer, application layer and various other layers [24]. Different levels of communication protocols are used for communication and data transmission. The specific digital media technology architecture model diagram is shown in Figure 2.

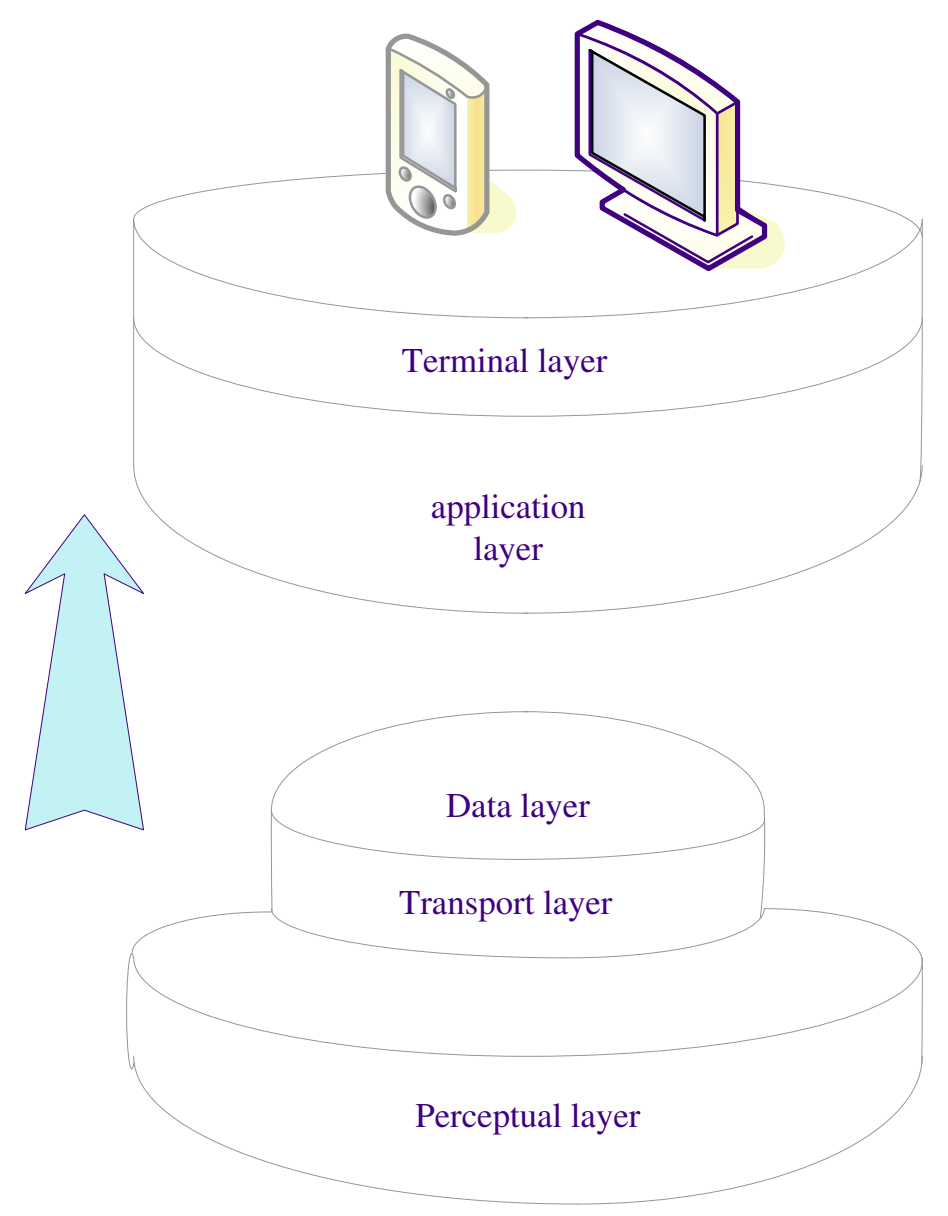

Figure 2. Architecture of Internet of things

The perception level of the digital media Internetof Things consists of sensors, RFID, written codes, and other tracking terminals. Mainly use Wifi, GPRS, ZigBee protocol to send data, and send the collected data to the higher-level structure Internet of Things system. The transport layer usually 
consists of media software and material portals [25]. In the Internet of Things architecture, through the use of media software, the recognition level of complex structures can be protected, and a comprehensive management interface that realizes the upper structure can be provided. Rapid manufacturing application of the digital media Internet of Things. The data layer is a data set, and data is sent using UDP, TCP and other protocols. The data layer mainly sends data to the application layer of the digital single Internet through methods such as FTP and HT-TP. In order to realize the collection and transmission of data, these different levels together constitute the architecture of the Internet of Things Osigs.

The data network transmission layer needs to provide standardized instructions for data collection equipment and comprehensive resource management. Different levels of network transmission need to include material entry, software drivers and interfaces. The material portal includes Wifi interface and RS485, RS232 and other interfaces. There are many outputs for different levels of network transmission, including various interfaces such as RJ45, Wifi, and LTE. Users can choose various output interfaces according to actual needs. The control program layer of the different layers of the transmission network needs to improve the understanding of the management of the device driver and the above-mentioned device control program. The above equipment does not need to care about the internal operating state of the machine, just call the relevant driver.

The data sharing layer is scattered between the e-commerce application layer and the data layer of the Internet. The data sharing center is a data processing center and center for data acquisition and data provision services of various applications of agricultural Internet e-commerce.

\section{Application Research Analysis of Digital Media Technology Based on 5g Internet of Things}

\section{Virtual Reality Technology as the Carrier}

\subsection{Comparison of Digital Media Based on $5 g$ Internet of Things Technology and Digital Media} Based on Traditional Network Technology

The production of digital media content requires $5 \mathrm{G}$ network support. As end users are increasingly demanding virtual content quality and real-time performance, in fact, the demand for ultra-high-speed networks for content production is increasing day by day. Related technologies include real-time and panoramic reception of content collection addresses, reconstruction of cloud 3D in the content processing direction, adaptation, splicing, spatial calculation, and content reproduction directions of virtual and actual WebXR scenes.

It is difficult for $4 \mathrm{G}$ networks to achieve higher visual input through virtual reality services. According to the cloud-based network architecture, the growing eye display technology shows higher bandwidth requirements. In Table 1, using angle analysis, field of view, color depth, update rate, and focal plane as the main measurement indicators of visual tilt, it can be seen that the multiplier effect and sufficient experience level can be used to speculate that the initial range of the broadband is not compressed Reached to 5 Tbit/s.

Table 1. Network capability requirements of near eye display technology

\begin{tabular}{|c|c|c|c|}
\hline Display effect & $\begin{array}{l}\text { Fixed depth of } \\
\text { focus/Gbps }\end{array}$ & $\begin{array}{l}\text { Multifocal } \\
\text { display/Gbps }\end{array}$ & $\begin{array}{l}\text { Light field } \\
\text { display/Gbps }\end{array}$ \\
\hline $\begin{array}{c}1080 \mathrm{P}(1920 * 1080) / 90 \\
\mathrm{~Hz}\end{array}$ & 0.53 & 4.18 & 0.53 \\
\hline
\end{tabular}




\begin{tabular}{|c|c|c|c|}
\hline $2 \mathrm{~K}(2560 * 1440) / 90 \mathrm{~Hz}$ & 0.94 & 7.43 & 0.94 \\
\hline $\begin{array}{c}4 \mathrm{~K}(3840 * 2560) / 120 \mathrm{H} \\
\mathrm{z}\end{array}$ & 3.4 & 26.5 & 3.4 \\
\hline $\begin{array}{c}8 \mathrm{~K}(7680 * 4620) / 120 \mathrm{H} \\
\mathrm{z}\end{array}$ & 11.13 & 88.98 & 11.13 \\
\hline
\end{tabular}

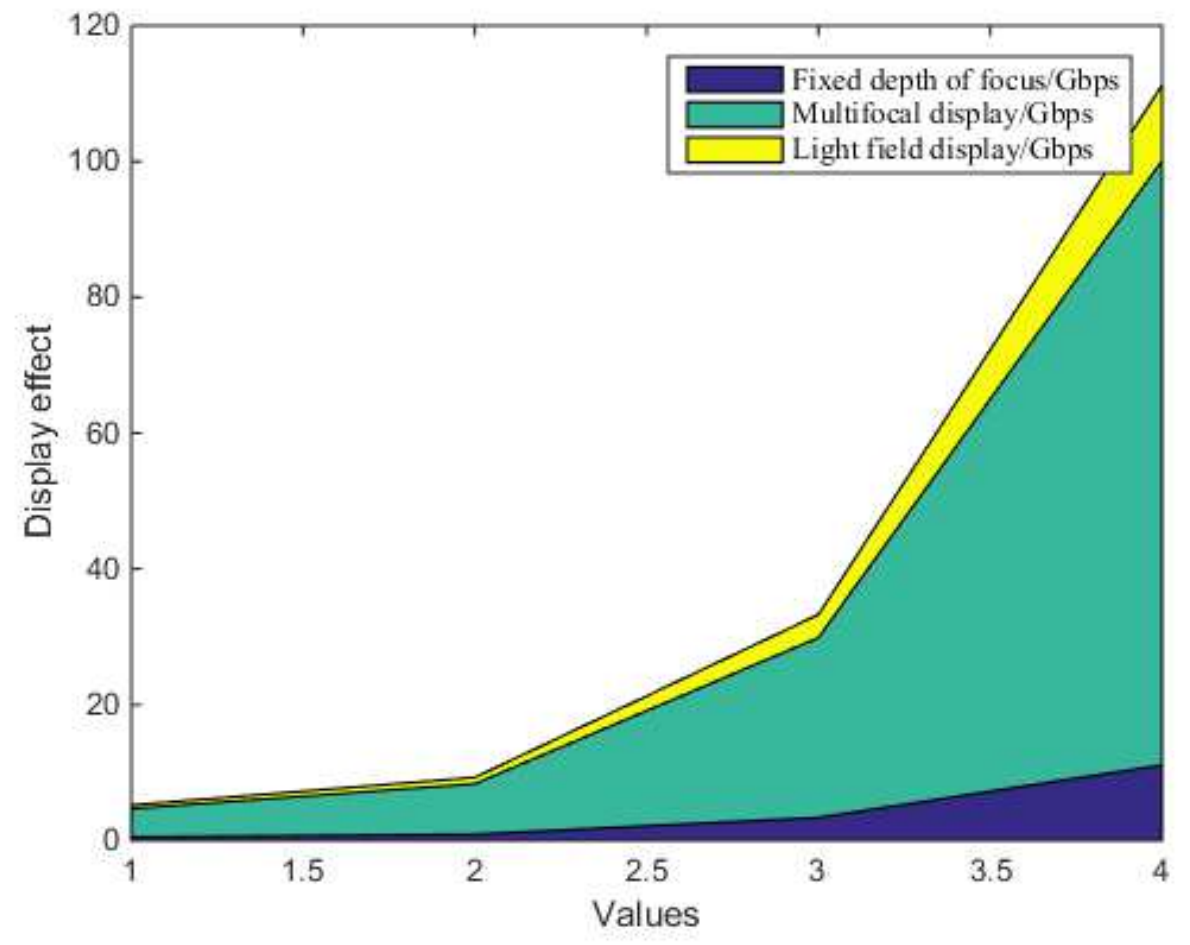

Figure 3 . Network capability requirements of near eye display technology

In addition, as shown in Figure 3, in a multi-focus display technology with 8 focal points simultaneously focusing, a $4 \mathrm{~K}$ monitor operator network with a maximum transmission area of 264Gbps is required. In the case of holographic display technology, since LCos SLM loads and displays holographic coded images, the operator's network not only meets the bandwidth requirement of $3 \mathrm{Gbps}$, but also meets multiple holog lars for the light field information of the projected image. You must perform prefix calculations. In order to perform holographic calculations, the light field information of the image to be displayed is converted into clouds. In the analysis of $4 \mathrm{~K}$ images, the bandwidth required by the upstream network must reach $3.3 \mathrm{Gbps}$. In the case of a picture update rate of $120 \mathrm{~Hz}$, the time used to calculate a single hologram must be less than $3 \mathrm{~ms}$.

Table 2.5G broadband and delay requirements of devices with different resolutions and refresh rates in the Internet of things

\begin{tabular}{|c|c|c|c|c|}
\hline Device name & Device resolution & $\begin{array}{c}\text { Screen refresh } \\
\text { rate/Hz }\end{array}$ & $\begin{array}{l}\text { Broadband } \\
\text { demand/Gbps }\end{array}$ & $\begin{array}{l}\text { Delay } \\
\text { requirement }\end{array}$ \\
\hline Shadow VR & $2 \mathrm{~K}(2560 * 1440)$ & 76 & 1.2 & 14 \\
\hline
\end{tabular}




\begin{tabular}{|c|c|c|c|c|}
\hline Action One & $2 \mathrm{~K}(2560 * 720)$ & 91 & 0.64 & 12 \\
\hline HTC Vive Focus & $3 \mathrm{~K}(2880 * 1600)$ & 76 & 1.4 & 14 \\
\hline Idealens K3+ & $4 \mathrm{~K}(3840 * 2160)$ & 73 & 2.4 & 15 \\
\hline
\end{tabular}

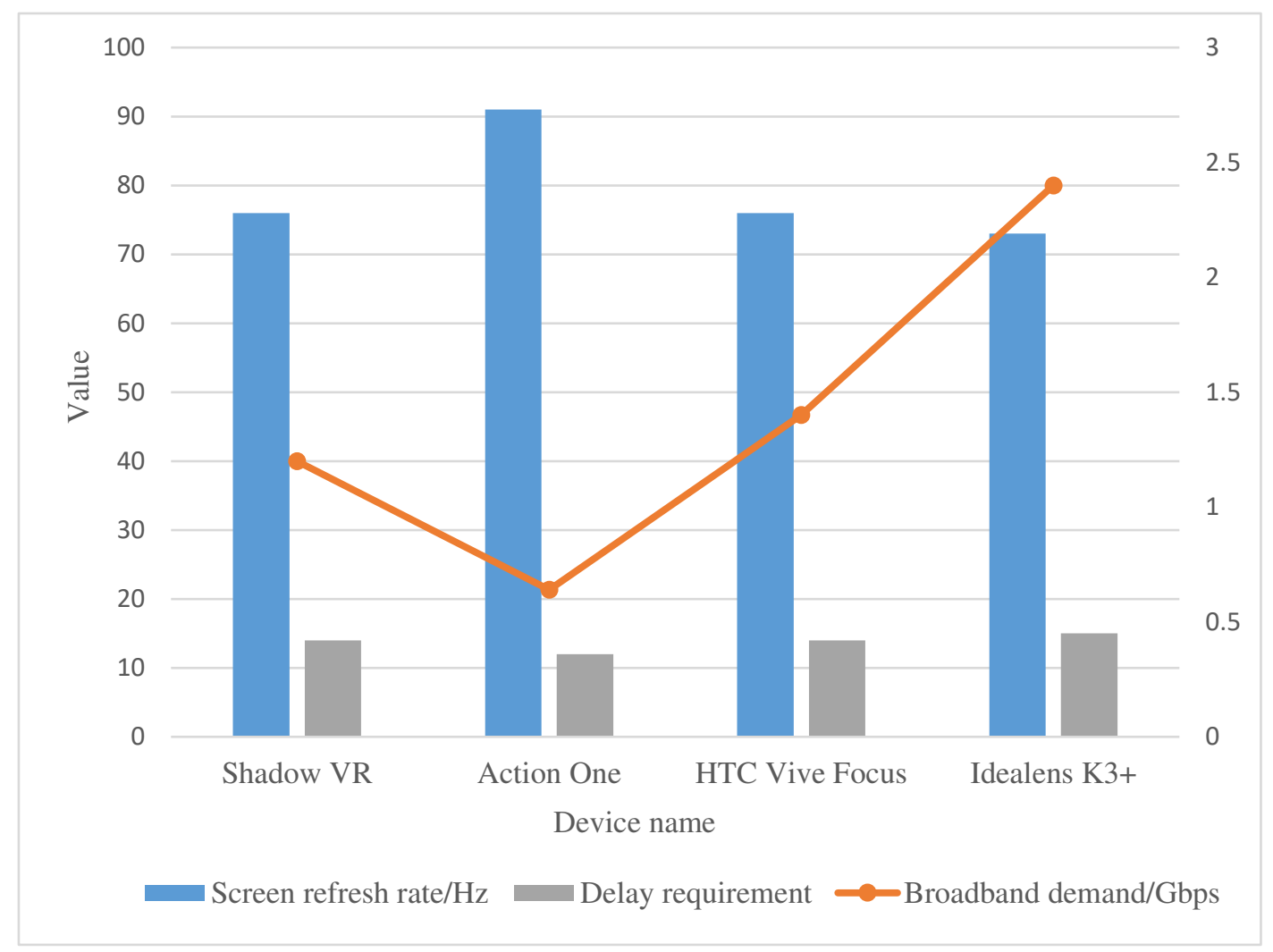

Figure 4 .5G broadband and delay requirements of devices with different resolutions and refresh rates in the Internet of things

As can be seen in Table 2 and Figure 4, devices with different resolutions in the Internet of Things have different requirements for refresh rate, bandwidth, and delay. Among them, the higher the resolution of the device, the slower the refresh rate, and higher requirements for broadband speed, but the delay requirements will increase accordingly. In devices with low resolution, the refresh rate is high, and the network speed requirement is only $0.64 \mathrm{Gbps}$, which satisfies the needs of most ordinary users.

\subsection{The Development of Digital Media Technology Based on Virtual Reality Technology}

(1) Development of key technologies of virtual reality 


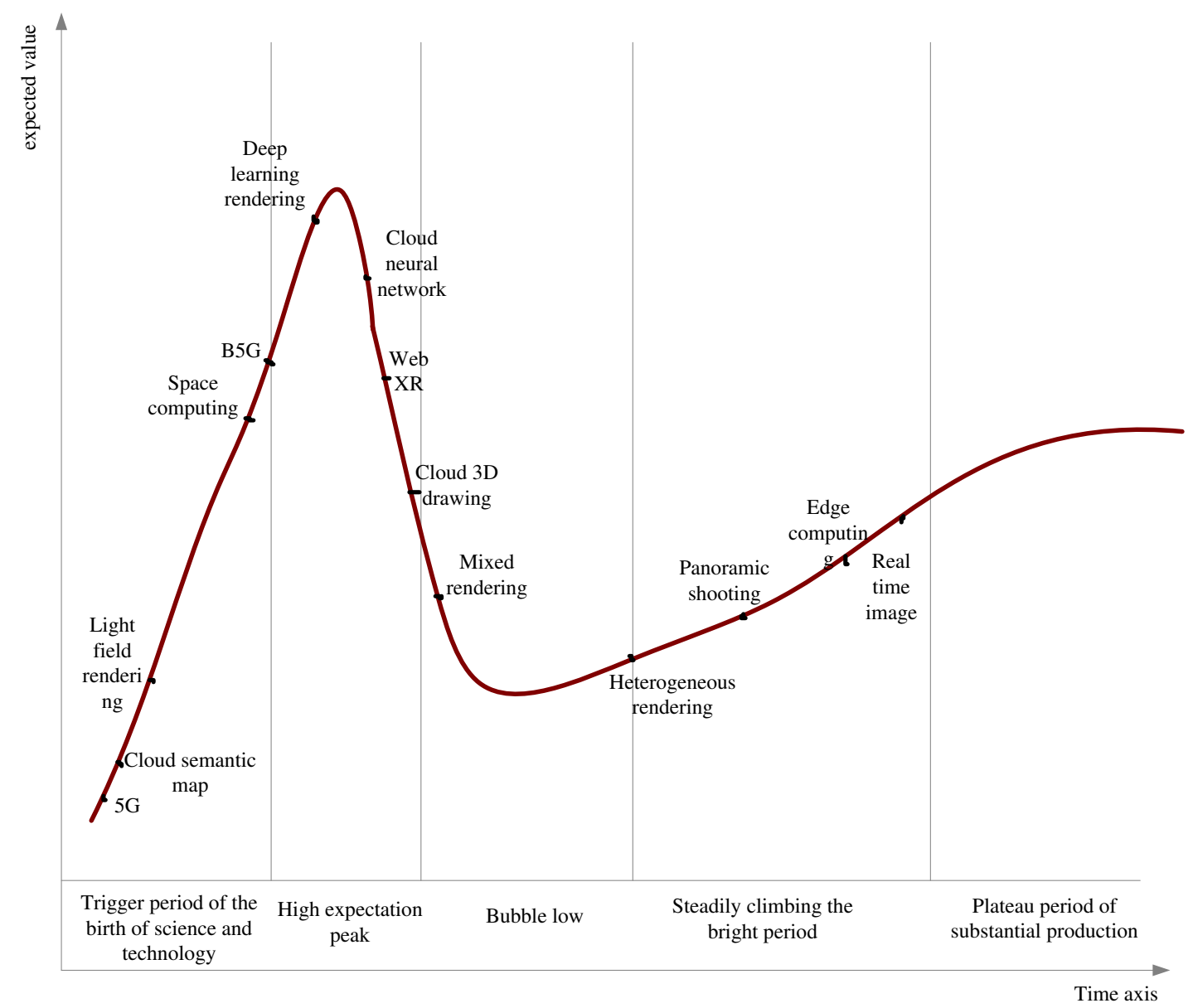

Figure 5. Maturity curve of key technologies of $5 \mathrm{~g}$ cloud virtual reality

According to the experience and lessons expressed by Gartner's technology maturity curve, as shown in Figure 5, the 5G virtual reality technology curve is planned. The following analysis summarizes the industrialization process of various virtual reality technologies that are closely related to $5 \mathrm{G}$. From the innovation of virtual reality technology, 5G+ will be distributed in the peak period of continuous upgrading, low bubble period and excessive expectations. It is expected to be within 3 years, mainly in the mature network field and broadcasting technology. In 2 to 5 years, the technology developed in the basic stage mainly focused on the computational efficiency of complex environments, scripts and content in the cloud, accounting for nearly half. In 5 years, we will infiltrate network applications from the virtual environment to the real environment and look forward to providing thought-reality fusion functions. In order to provide better user experience, it is mainly the light field project and hybrid performance of more than 10 years of mature technology.

(2) $5 \mathrm{G}$ boosts the development of virtual reality technology and digital media technology 


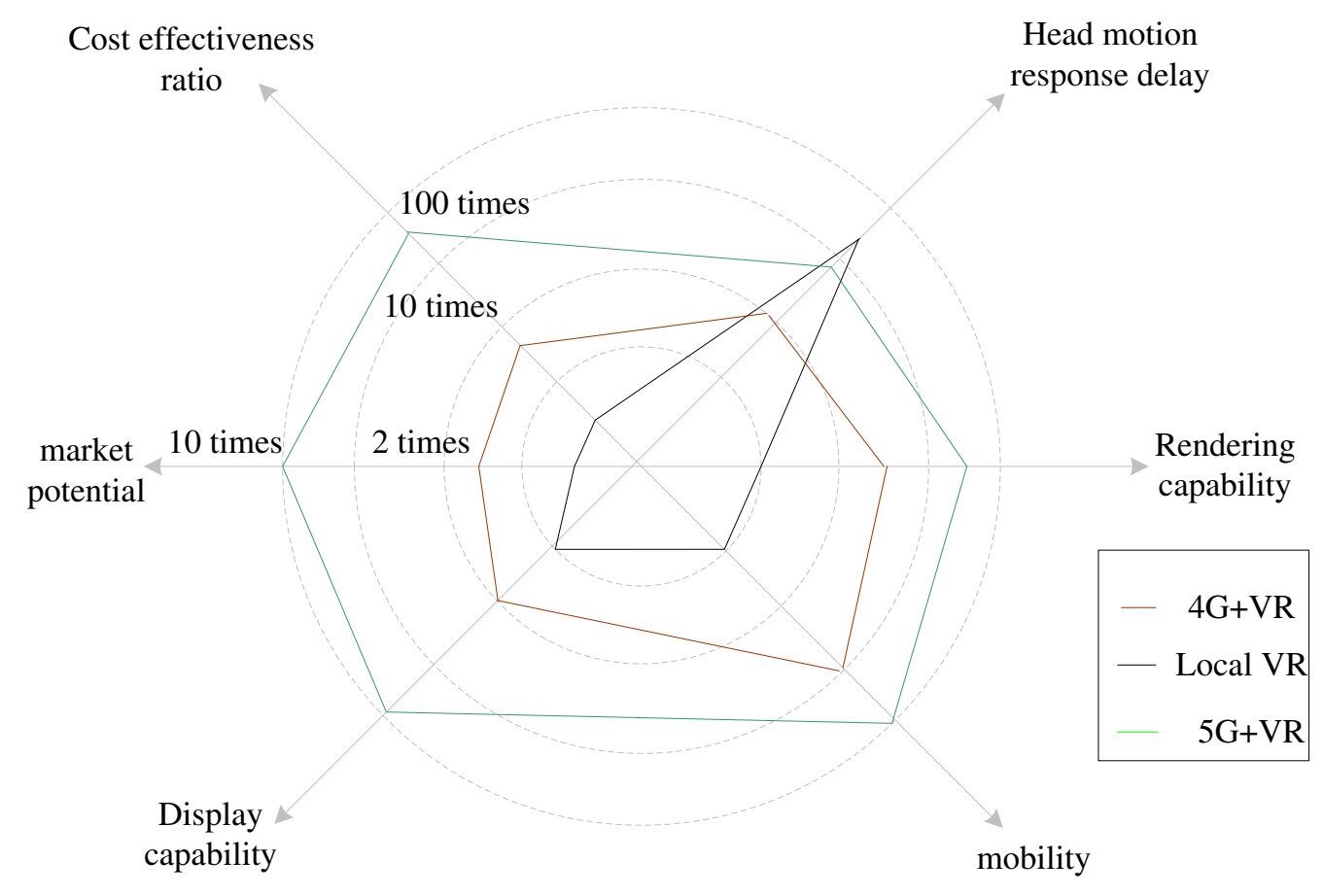

Figure 6. Comparison of local / 4G / 5G + VR solutions

As shown in Figure 6, compared with the local virtual reality technology path based on cloud $4 \mathrm{G}$, the virtual reality technology based on cloud $5 \mathrm{G}$ greatly improves the performance, function and cost. This can be summarized as head action response delay (MTP). Moreover, performance features, appearance, flexibility of use, market capacity and cost-effectiveness. The industry generally believes that the response time delay of head movement needs to be controlled within $20 \mathrm{~ms}$. If you don't do that, dizziness is prone to occur. In other words, the corresponding new perspective must not be displayed. More than 20 milliseconds should not be displayed all. Or, there is no image in the field of view. Taking into account that the price of the terminal may be completed within 20 seconds, because it cannot handle the price of the cloud on the basis of the local price.

In 4G networks, $4 \mathrm{G}$ cloud + small GPU is used to calculate cloud performance and visualization. In this way, the processing pressure of the terminal will be reduced, and the delay of the network will further occur. The standard $4 \mathrm{G}$ air interface delay is $10 \mathrm{~ms}$ between $28 \mathrm{~ms}$. In the $5 \mathrm{G}$ network, due to the high bandwidth and low latency network characteristics, the $5 \mathrm{G}$ network will reduce the air connection delay of $1 \mathrm{~ms}$. Adopt $5 \mathrm{G}+\mathrm{GPU}$ cloud group method and delay control. The goal is to reach the peak of the machine and high standards within 10ms.

Various virtual reality applications are expanding by providing solutions for users to expand high-speed mobile phones over 100Mbps. In the high-speed application schemes of mobile vehicles and high-speed rail, the service functions and necessary continuity of operation can be guaranteed at all stages. As a new generation of human-computer interaction platforms, market possibilities, cost-to-effects and other economic factors, virtual reality is an independent market development with a slow release stage, and application solutions and user experience are local terminal restrictions. Compared with the development of the autonomous island version, the possibility of the virtual reality market depends on the hidden network price of the virtual world, compared with the Metropolitan Law and the scale of the world virtual reality industry from 2017 to 2022. 
4.3 The Status Quo of the Application of Digital Media Technology Based on $5 g$ Internet of Things Virtual Reality Technology as the Carrier

(1) Application proportions of 5G Internet of Things technology, virtual reality technology, and digital media technology in the four industry sectors

This paper selects four major areas of education, construction, industry, and medical care to compare the application of 4G, 5G, VR technology, and digital media technology. The results are shown in Table 3.

Table 3.5G application proportion of Internet of things technology, virtual reality technology and digital media technology in four industries

\begin{tabular}{|c|c|c|c|c|}
\hline Type/\% & Education & Architecture & Industry & Medical care \\
\hline $4 \mathrm{G}$ & 96 & 95 & 94 & 93 \\
\hline $5 \mathrm{G}$ & 30 & 35 & 33 & 36 \\
\hline VR technology & 21 & 35 & 20 & 40 \\
\hline $\begin{array}{l}\text { Digital media } \\
\text { technology }\end{array}$ & 50 & 60 & 40 & 42 \\
\hline
\end{tabular}

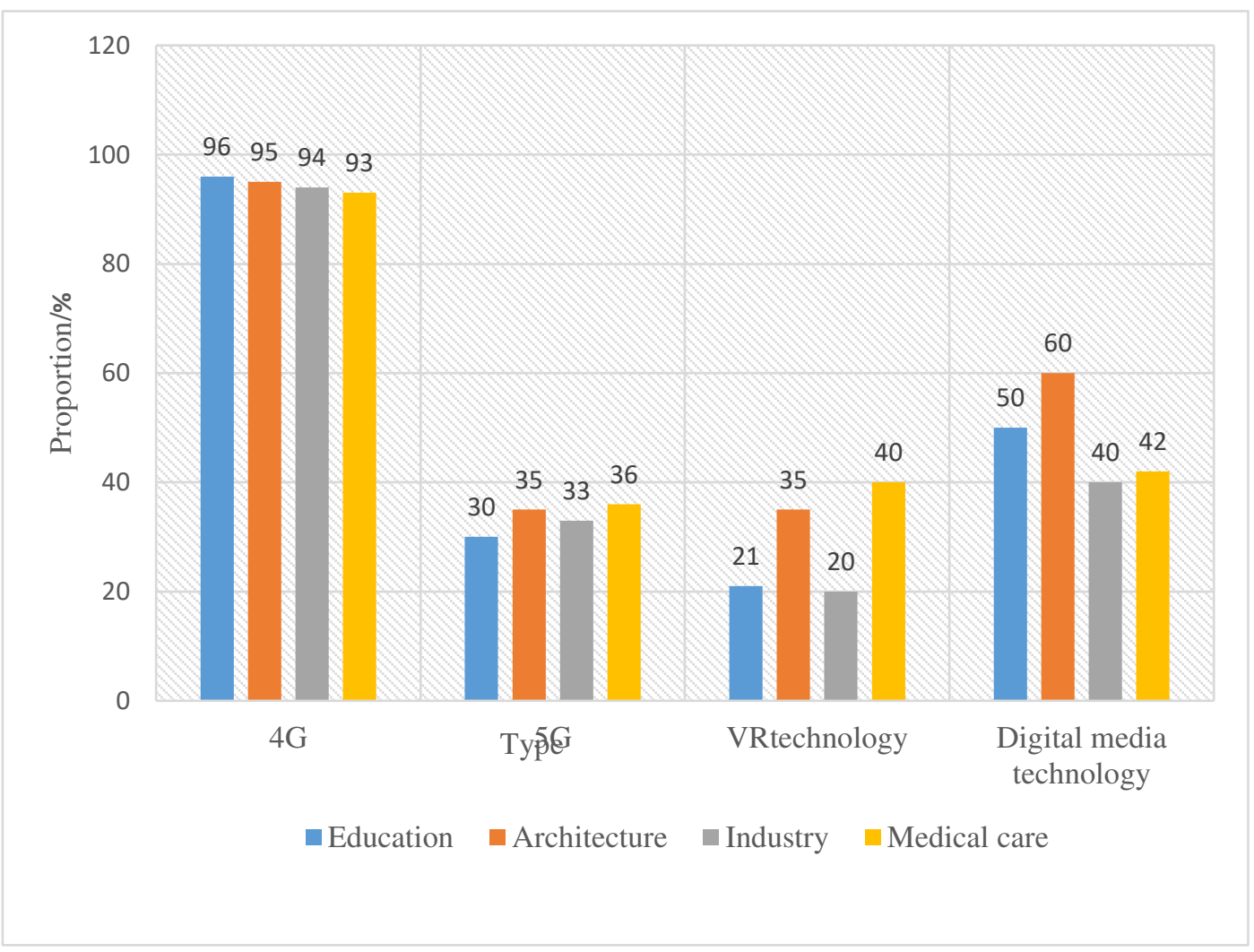

Figure 7. Application proportion of four emerging technologies in various industries 


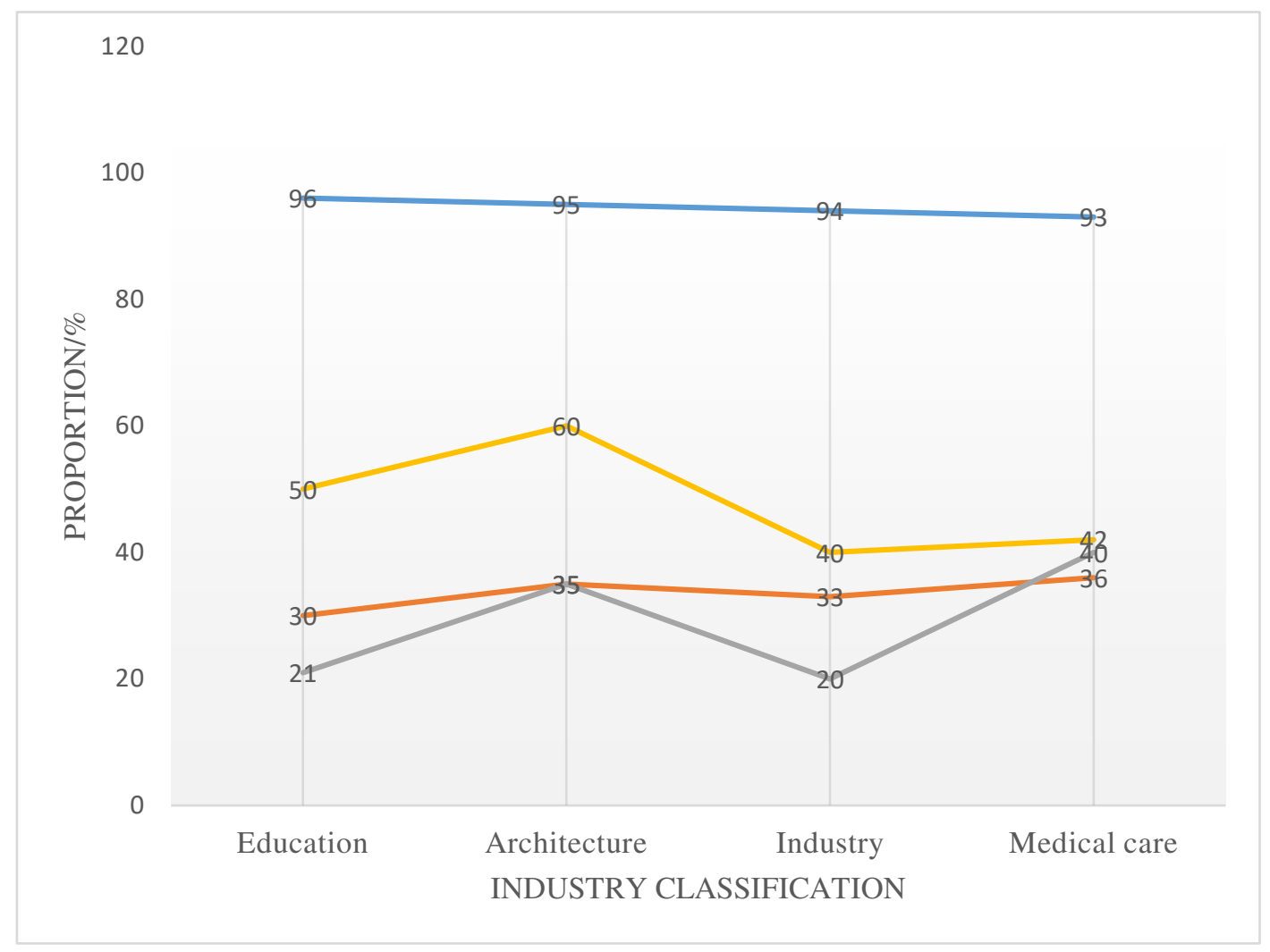

Figure 8. Use of emerging technologies in various fields

As can be seen from Figures 7 and 8, in 4G, 5G, VR, and digital media technologies, 4G has the widest coverage and the largest application range, and is now relatively mature; however, emerging technologies have emerged after the rise and are used in real life There is still a lot of trial research to be carried out on a large-scale and large-scale promotion and application.

4.4 Analysis of the Optimization of Digital Media Technology and Video Technology Based on $5 \mathrm{~g}$ Internet of Things with Virtual Reality Technology as the Carrier

In order to verify the effectiveness and feasibility of the improved video technology, the experiment uses the improved technology and traditional video technology as a comparison to conduct an analysis. The parameter settings are shown in the table.

Table 4. Experimental parameter setting

\begin{tabular}{|c|c|}
\hline \multicolumn{1}{|c|}{ name } & Dispose \\
\hline operating system & Windows 10 \\
\hline processor & 4-core processor \\
\hline Memory & $8 \mathrm{~GB}$ \\
\hline Hard disk & $128 \mathrm{~GB}$ \\
\hline a main board & blue sky P150HMx \\
\hline Video card & Nvidia GeForce GTX 560M \\
\hline
\end{tabular}

In the case of a certain number of experiments, the video overhead is used as an indicator, and the traditional video technology and the improved video technology are used for comparison of the experimental analysis. The results are shown in Figure 9. 


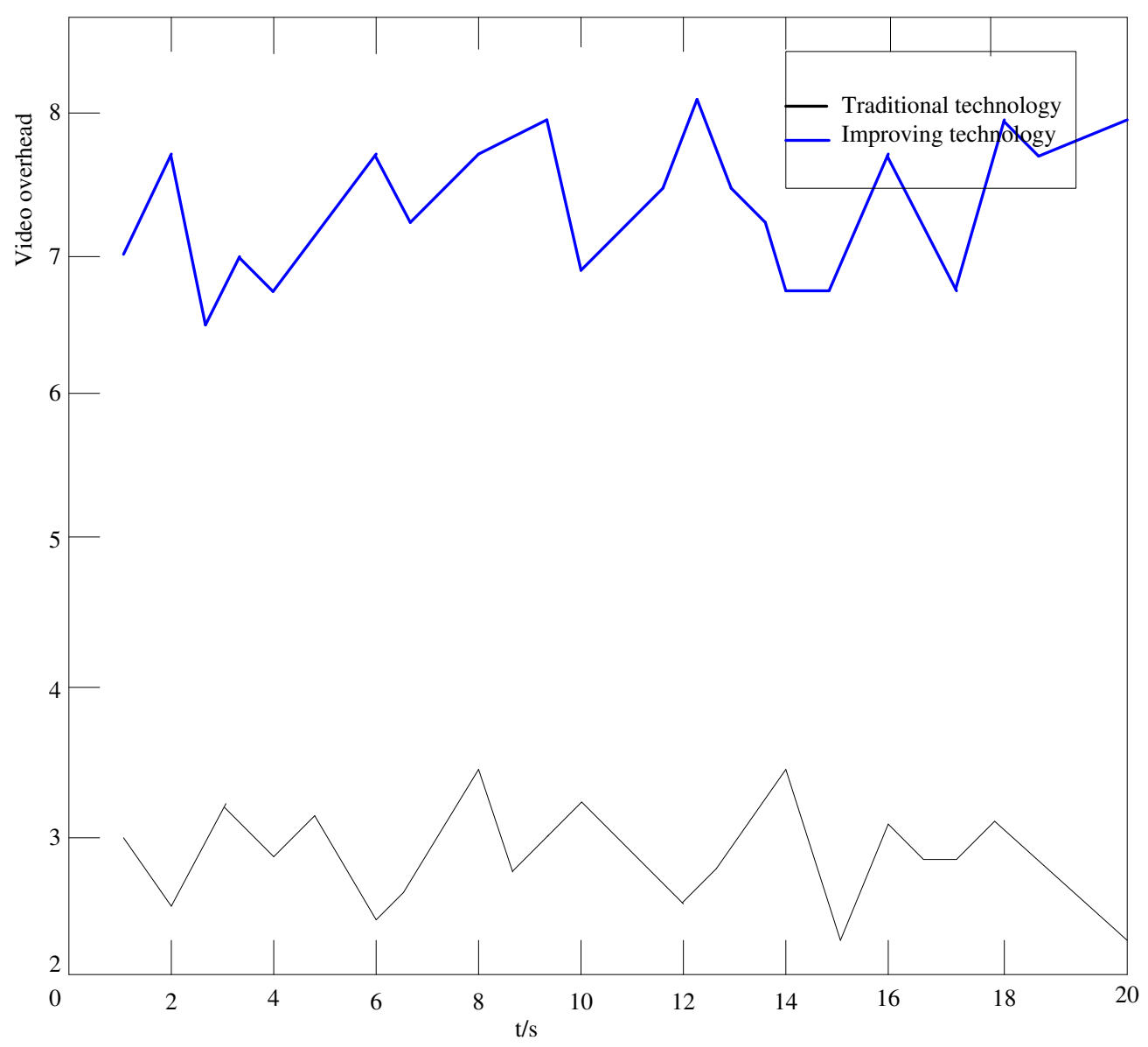

Figure 9 .Contrast diagram of video transmission quality

It can be seen from Figure 9 that if the execution time is uncertain, the traditional video technology is used. As the execution time increases, the video cost will change many times, but the total cost of the video is about $7 \times 105$, which is not obvious degree of declining. When using improved video technology, if the running time becomes longer, the video load will change in many places. The maximum amount of the overall video is $4 \times 105$, and the minimum amount is $2.1 \times 105$. It is about $3 \times 105$, which is about $4 \times 105$ less than traditional video technology, and has specific advantages.

\section{Conclusion}

This article mainly focuses on the application of digital media technology based on $5 \mathrm{G}$ Internet of Things virtual reality technology as a carrier. Through in-depth learning of virtual reality technology, Quick Time VR technology, Tilt Brush VR technology, Oculus Quill technology and digital media technology, a virtual reality Realistic three-dimensional digital media model and digital media Internet of Things system architecture, analyzed the comparison between 5G technology and traditional technology, and the proportion of 5G Internet of Things virtual reality technology and digital media technology in education, construction, industry and medical fields.

The innovation of this article is that the first combination of qualitative research and quantitative research fully combines research data with practical application value to show the practical value of this research; the second combination of theoretical research and empirical research, in the in-depth study of virtual Based on the theoretical basis of real technology and digital 
media technology, empirical investigations in various fields are combined.

There are still some obstacles to the research in this paper, mainly due to the immaturity of virtual reality technology. For example, the user's range of activities is limited, and most virtual reality equipment can only move in place; the price of VR is too high, the technical equipment is too complicated and flexible, Not high; because virtual reality technology is an emerging technology, its development and design have not yet been standardized, and the technical standards lack uniformity.

\section{Acknowledgements}

This work was supported by

- $\quad$ NSFC of China (61907026)

- A Project of Shandong Province Higher Educational Science and Technology Program (J18KA392)

This work was supported by the Excellent Talent Foundation of China West Normal University (No: 17YC497)

\section{Author Contributions}

All authors contributed to the study conception and design, and all authors commented on previous versions of the manuscript. All authors read and approved the final manuscript.

\section{Conflict of Interests}

These no potential competing interests in our paper. And all authors have seen the manuscript and approved to submit to your journal. We confirm that the content of the manuscript has not been published or submitted for publication elsewhere.

\section{Reference}

[1]Bastug E , Bennis M , Medard M , et al. Toward Interconnected Virtual Reality: Opportunities, Challenges, and Enablers[J]. IEEE Communications Magazine, 2017, 55(6):110-117.

[2] Vera L, Florella M, Sarale C , et al. Effects of virtual reality immersion and audiovisual distraction techniques for patients with pruritus[J]. Pain Research \& Management, 2016, 14(4):283286.

[3]Lee F L F , Chan J M . Digital media activities and mode of participation in a protest campaign: a study of the Umbrella Movement[J]. Information Communication \& Society, 2016, 19(1-2):4-22. [4]Riva G , Bacchetta M , Baruffi M, et al. Virtual Reality Environment for Body Image Modification: A Multidimensional Therapy for the Treatment of Body Image in Obesity and Related Pathologies[J]. Cyberpsychology \& Behavior, 2016, 3(3):421-431.

[5]Lenoir J , Cotin S , Duriez C , et al. Workshop On Virtual Reality Interaction and Physical Simulation (2005) F. Ganovelli and C. Mendoza (Editors) Interactive physically-based simulation of Catheter and Guidewire[J]. Journal of Preventive Medicine Information, 2017, 61(13):2132-2141. [6]Al-Kodmany, K. Visualization Tools and Methods in Community Planning: From Freehand Sketches to Virtual Reality[J]. Journal of Planning Literature, 2016, 17(2):189-211. 
[7]Rizzo A S , Koenig S T . Is Clinical Virtual Reality Ready for Primetime?[J]. Neuropsychology, 2017, 31(8):877-899.

[8]Cochrane T, Cook S, Aiello S, et al. A DBR framework for designing mobile virtual reality learning environments[J]. Australasian Journal of Educational Technology, 2017, 33(6):54-68.

[9]Khanduja V ? , Lawrence J E, Audenaert E. Testing the Construct Validity of a Virtual Reality Hip Arthroscopy Simulator[J]. Arthroscopy the Journal of Arthroscopic \& Related Surgery, 2016, 3(3):566-571.

[10]Peeters D , Dijkstra T . Sustained inhibition of the native language in bilingual language production: A virtual reality approach*[J]. Bilingualism Language \& Cognition, 2017:1-27.

[11]Mclellan, Hilary. Cognitive Issues in Virtual Reality[J]. Journal of Visual Literacy, 2016, 18(2):175-199.

[12]Serino S , Pedroli E , Keizer A , et al. Virtual Reality Body Swapping: A Tool for Modifying the Allocentric Memory of the Body[J]. Cyberpsychology \& Behavior, 2016, 19(2):127-133.

[13]Freeman D , Reeve S , Robinson A , et al. Virtual reality in the assessment, understanding, and treatment of mental health disorders[J]. Psychological Medicine, 2017, 47(14):1-8.

[14]Rosli H , Kamaruddin N . Visitor Experience's on Digital Media Technology for the Museum Exhibition in Malaysia: A Preliminary Findings[J]. International Journal of entific Research, 2020, 7(2):245-248.

[15]Dragiewicz M , Burgess J , Matamoros-Fernández, Ariadna, et al. Technology facilitated coercive control: domestic violence and the competing roles of digital media platforms[J]. Feminist Media Studies, 2018:1-17.

[16]Juditya S , Suherman A , Rusdiana A , et al. Digital Teaching Material "POJOK": One of The Technology Based Media In Physical Education Learning[J]. International Journal of Psychosocial Rehabilitation, 2020, 24(10):1774-1784.

[17]Lee F L F , Chan J M . Digital media activities and mode of participation in a protest campaign: a study of the Umbrella Movement[J]. Information Communication \& Society, 2016, 19(1-2):4-22. [18]Sohrabi B , Iraj H . Implementing flipped classroom using digital media: A comparison of two demographically different groups perceptions[J]. Computers in Human Behavior, 2016, 60(Jul.):514-524.

[19]Isabel Ruiz-Mallén, Heras M , Berrens K . Responsible research and innovation in science education: insights from evaluating the impact of using digital media and arts-based methods on RRI values[J]. Research in Science and Technological Education, 2020(2):1-22.

[20]Rosli H , Kamaruddin N . Visitor Experience's on Digital Media Technology for the Museum Exhibition in Malaysia: A Preliminary Findings[J]. International Journal of entific Research, 2020, 7(2):245-248.

[21]András Vajda, Gyngyvér Erika Tkés. Digital Media Use of Older Adults in Mure County, Romania[J]. Acta Universitatis Sapientiae Communicatio, 2019, 6(1):131-146.

[22]Galus A , Nesteriak Y . Digital media in a contemporary conflict - example of Ukraine[J]. rodkowoeuropejskie Studia Polityczne, 2019, 4:27-44.

[23]Caron X , Bosua R , Maynard S B , et al. The Internet of Things (IoT) and its impact on individual privacy: An Australian perspective[J]. Computer Law \& Security Review, 2016, 32(1):415 . 
[24]Khanouche M E , Amirat Y , Chibani A , et al. Energy-centered and QoS-aware services selection for Internet of Things[J]. IEEE Transactions on Automation ence \& Engineering, 2016, 13(3):1256-1269.

[25]Wollschlaeger M , Sauter T , Jasperneite J . The Future of Industrial Communication: Automation Networks in the Era of the Internet of Things and Industry 4.0[J]. IEEE Industrial Electronics Magazine, 2017, 11(1):17-27.

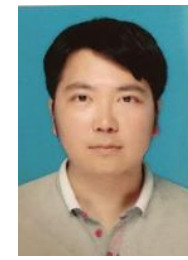

Xingchen Zhang was born in Jinan, Shandong. P.R. China, in 1979. He received the Ph.D from Shanghai University, P.R. China. Now, he works in School of Computer Sicence and Technology, Shandong Technology and Business University. His research interest include digital media technology and interactive media design.

E-mail: 201613590@sdtbu.edu.cn

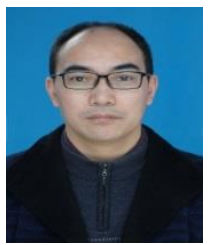

Zaiyi Pu was born in QU conty, Sichuan, P.R. China, in 1974. He received his M.S. degree in Computer application technology from China West Normal University in Nanchong, Sichuan, P.R. china. Now, he works in Education and Information Technology Center, China West Normal University. His research interest include information security,cloud computing and super polymerization. $\mathrm{He}$ has been engaged in the research for many years.

E-mail: zaiyipu@cwnu.edu.cn

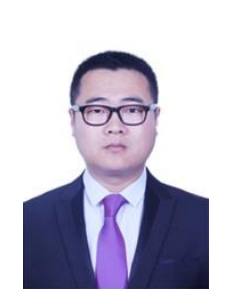

Xinbo Jiang received his B.S. degree and Ph.D. degree in computer science and technology from Shandong University, Jinan, China, in 2010 and 2015, respectively. $\mathrm{He}$ is a lecturer of Shandong Technology and Business University now. His research interests include computer vision and augmented reality. He hosts a National Natural Science Foundation of China, an Open Fund Project of Shandong Key Laboratory and a Project of Shandong Province Higher Educational Science and Technology

Program.

E-mail:xinboj@gmail.com 
Figures

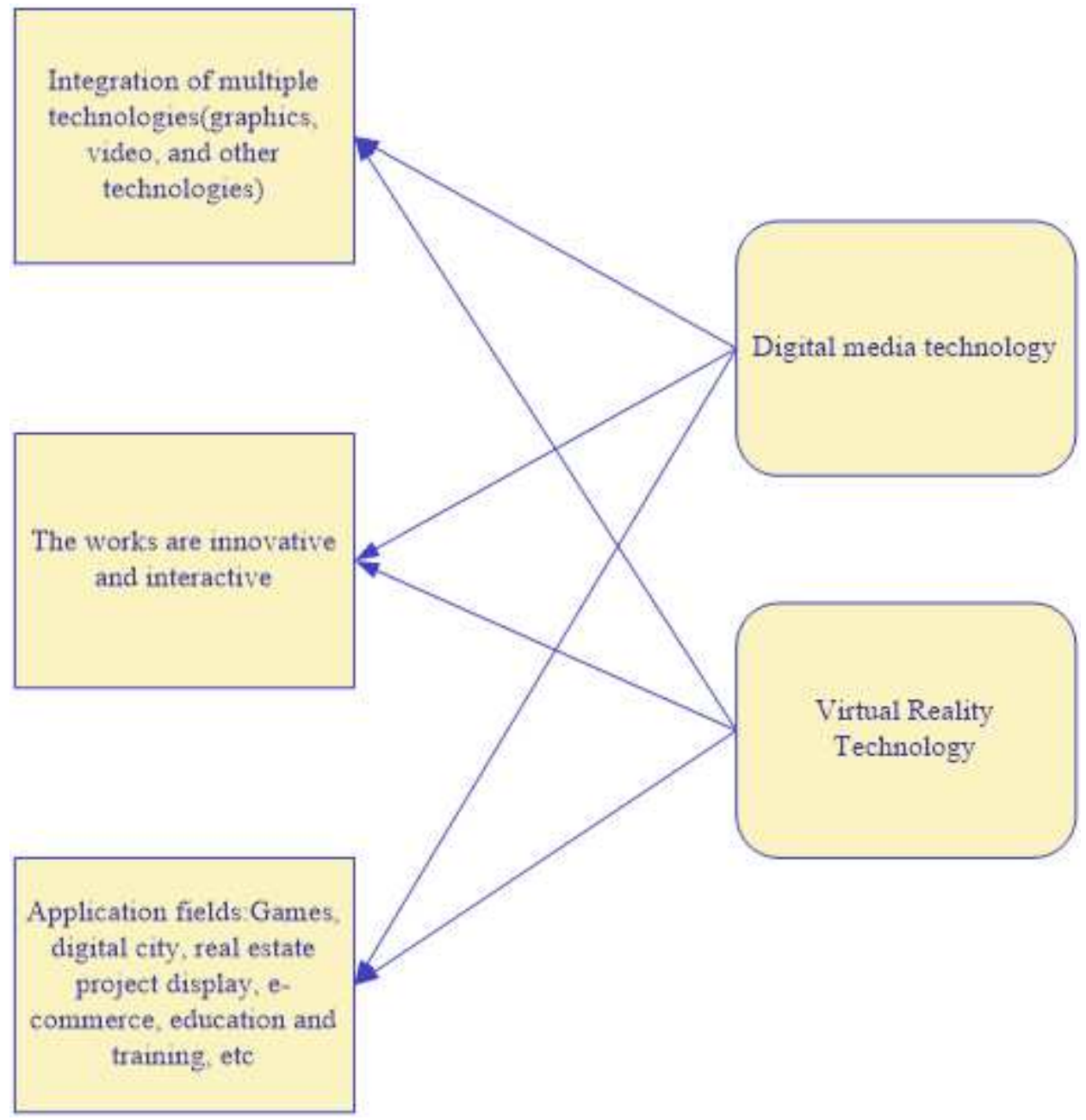

\section{Figure 1}

The relevance of virtual reality technology and digital media technology 


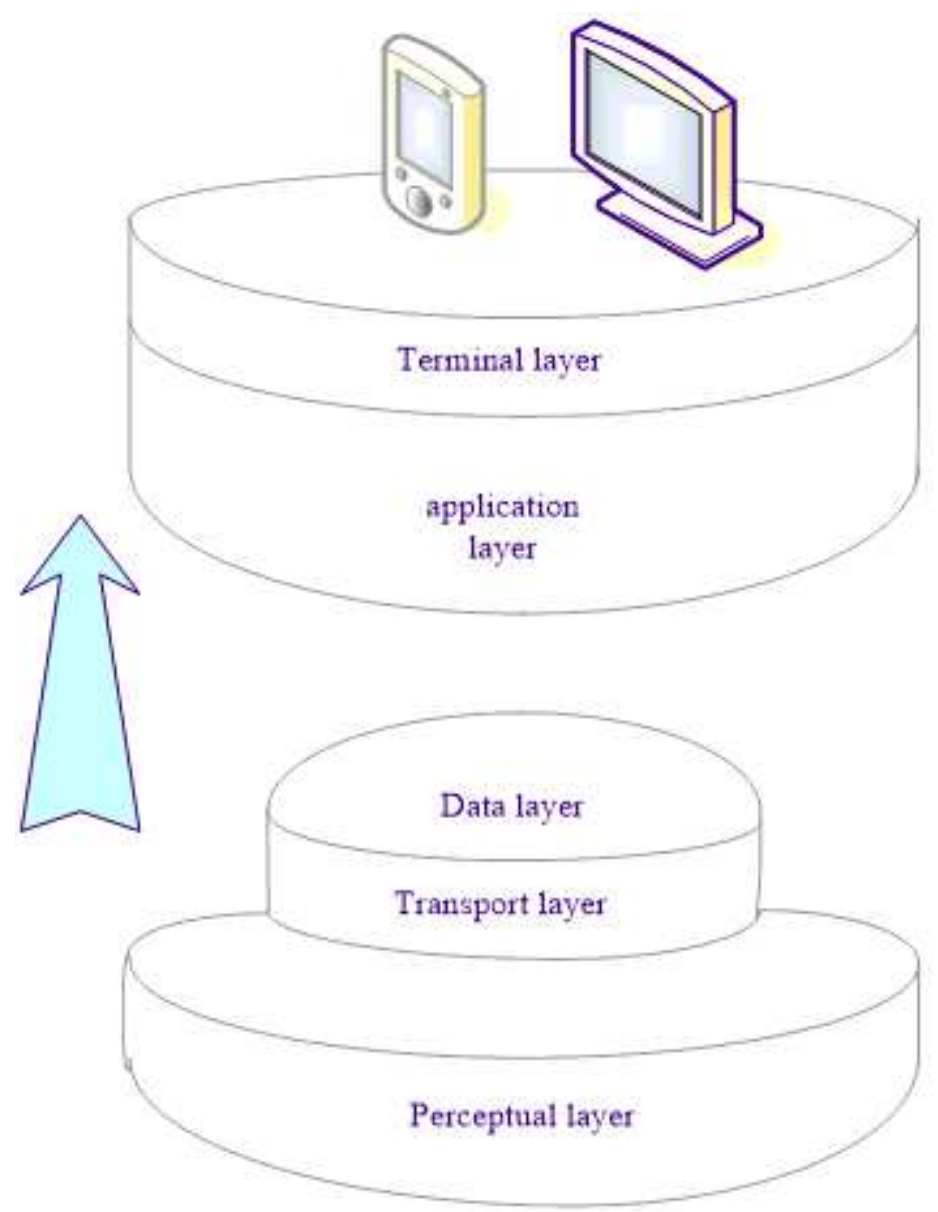

Figure 2

Architecture of Internet of things 


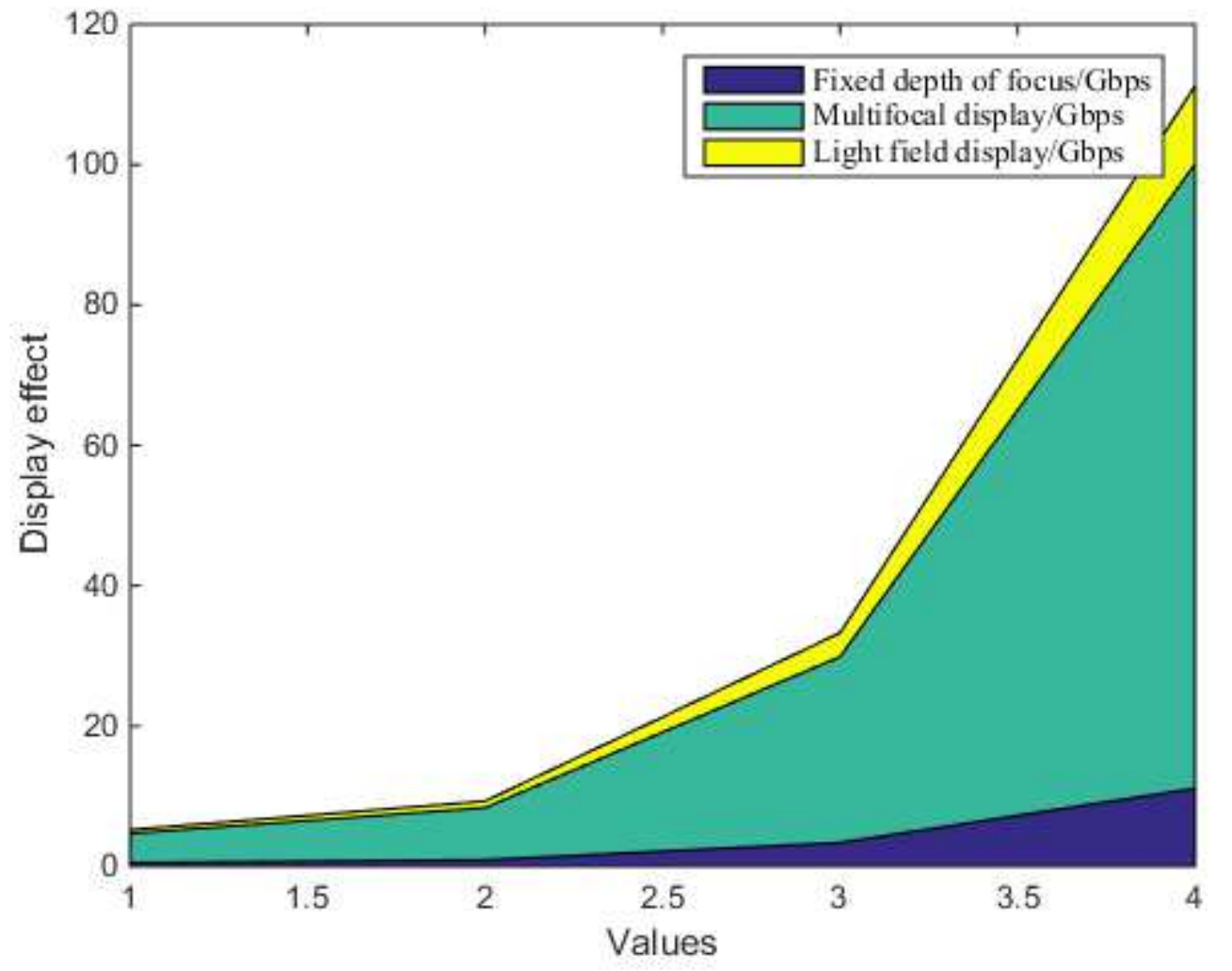

Figure 3

Network capability requirements of near eye display technology

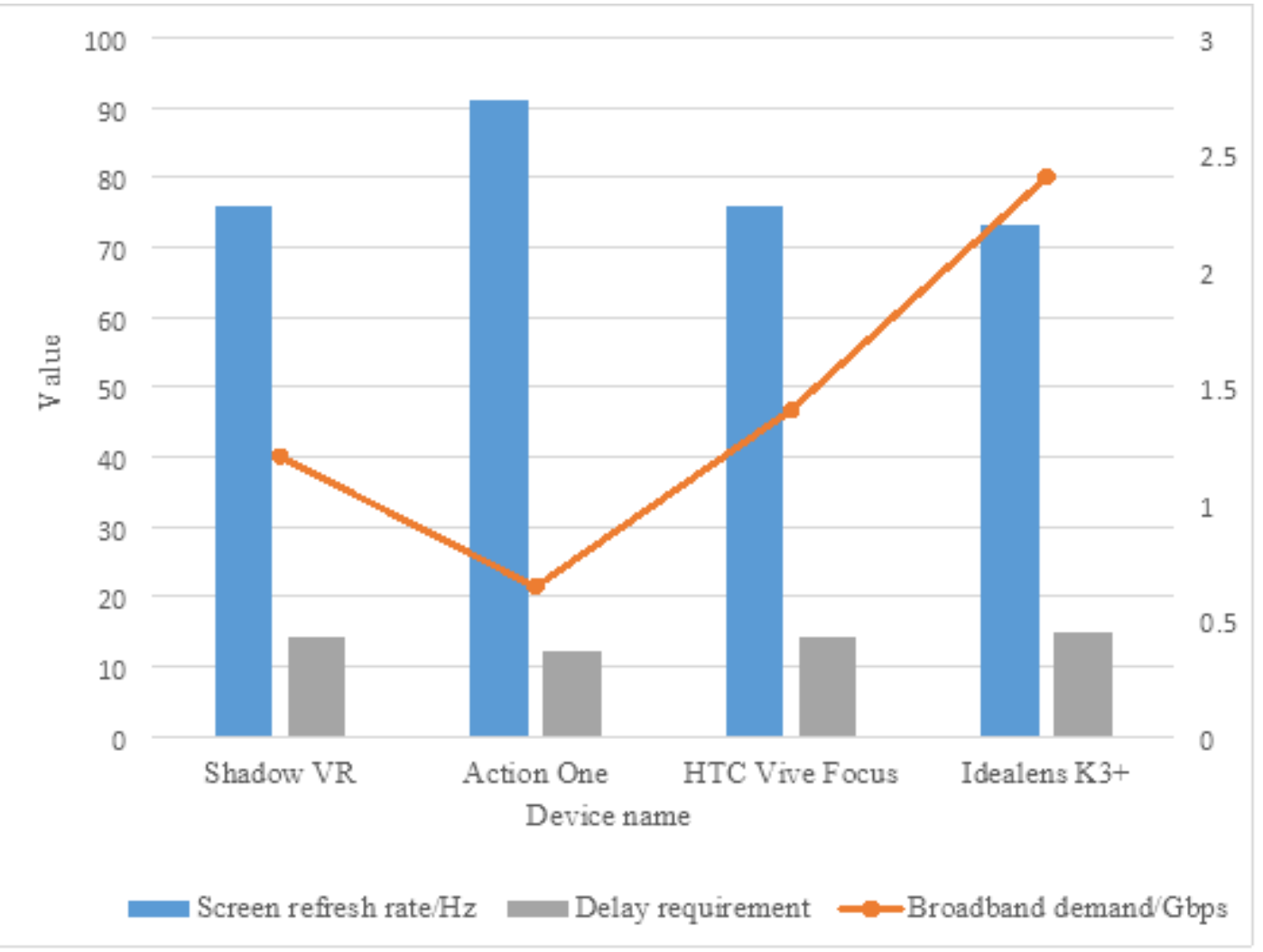

Figure 4 
$5 \mathrm{G}$ broadband and delay requirements of devices with different resolutions and refresh rates in the Internet of things

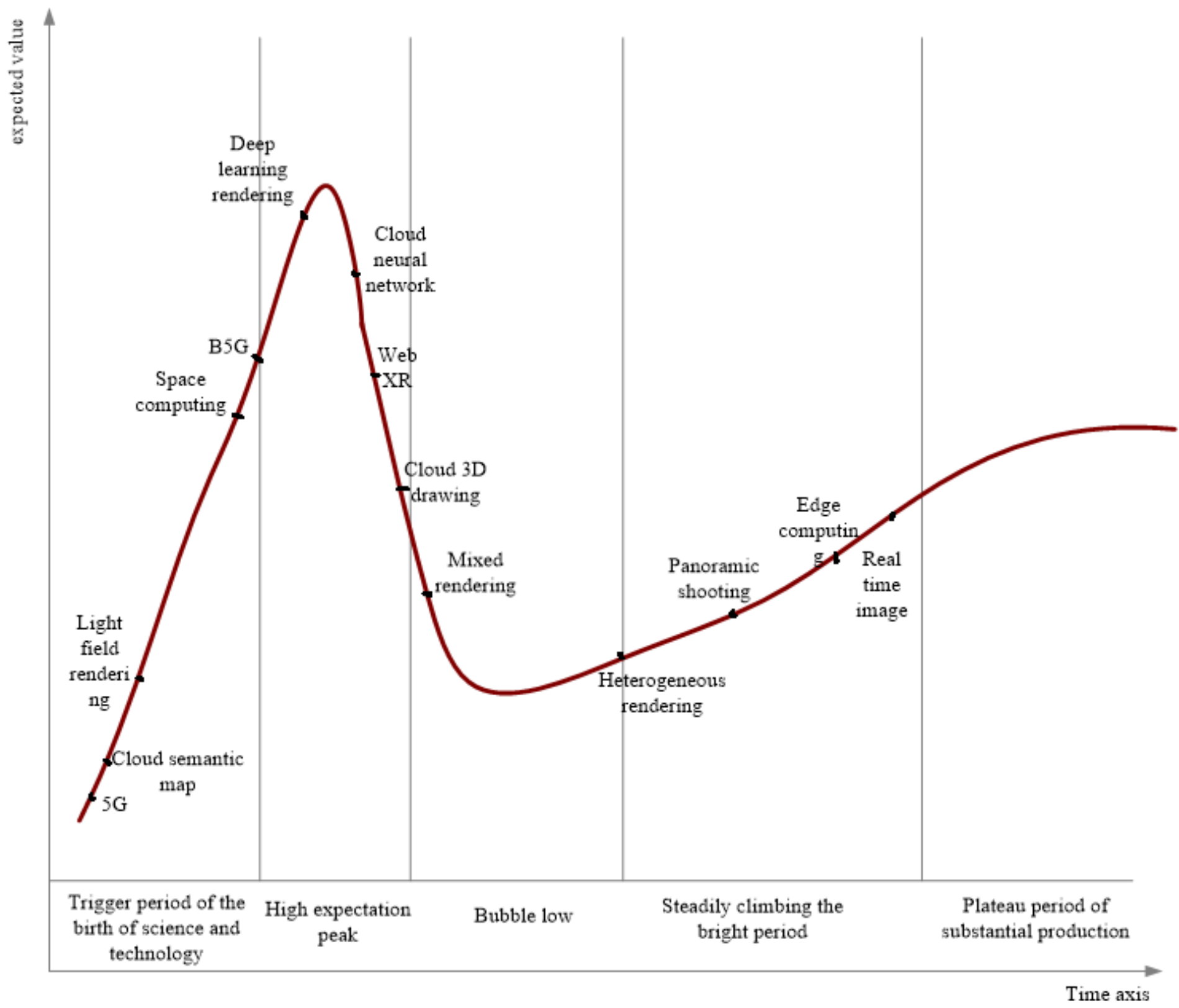

Figure 5

Maturity curve of key technologies of $5 \mathrm{~g}$ cloud virtual reality 


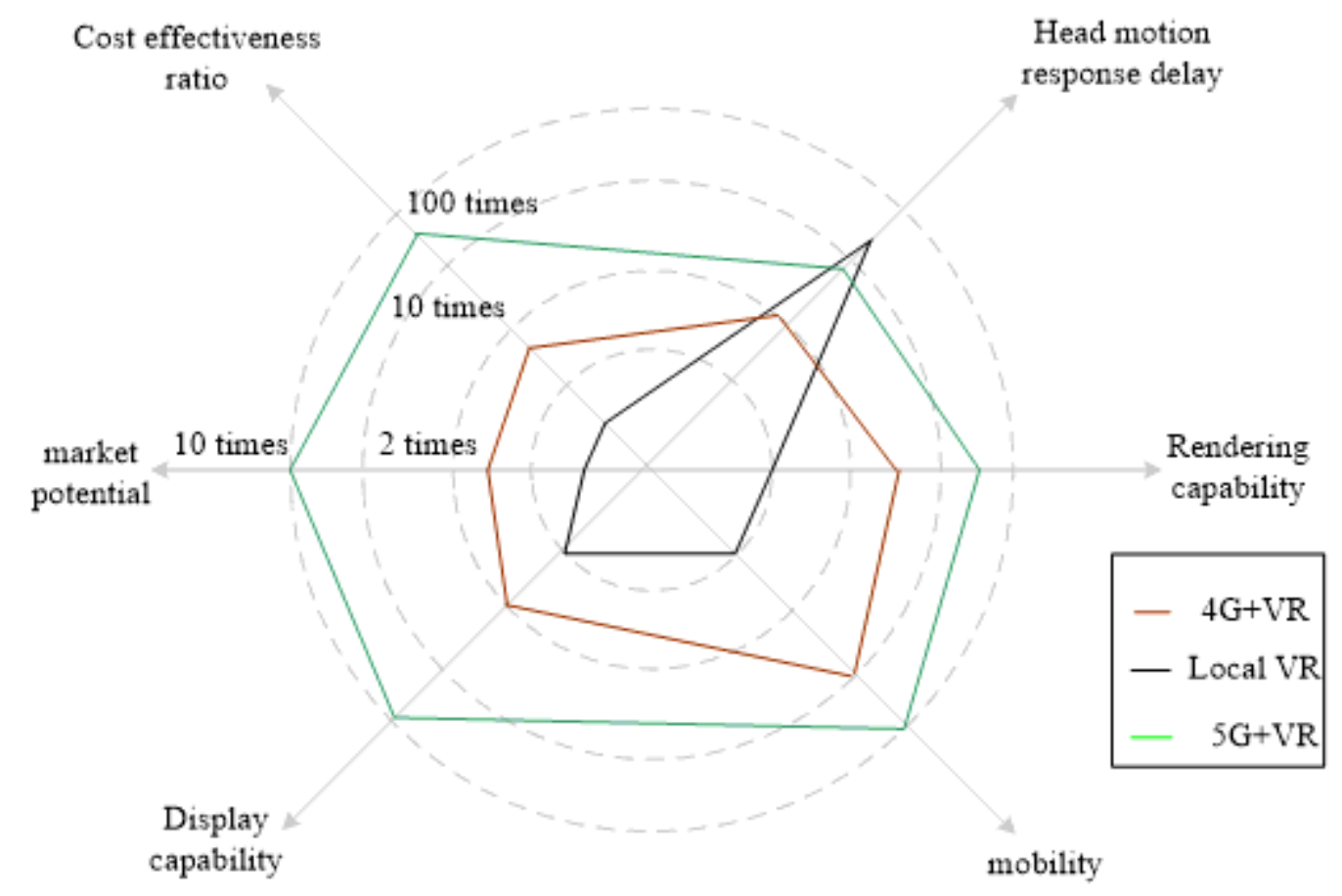

Figure 6

Comparison of local / 4G / 5G + VR solutions

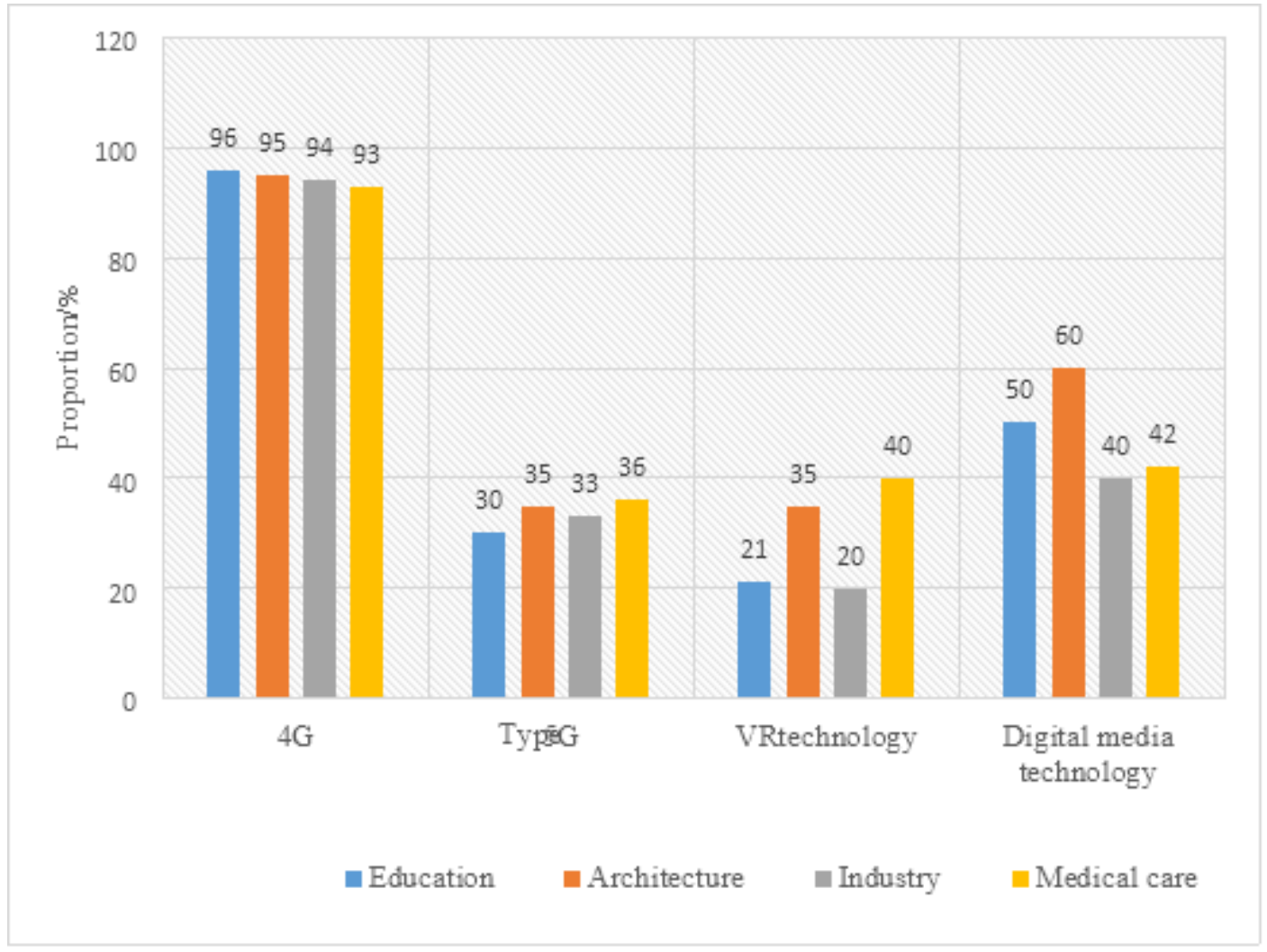

Figure 7

Application proportion of four emerging technologies in various industries 


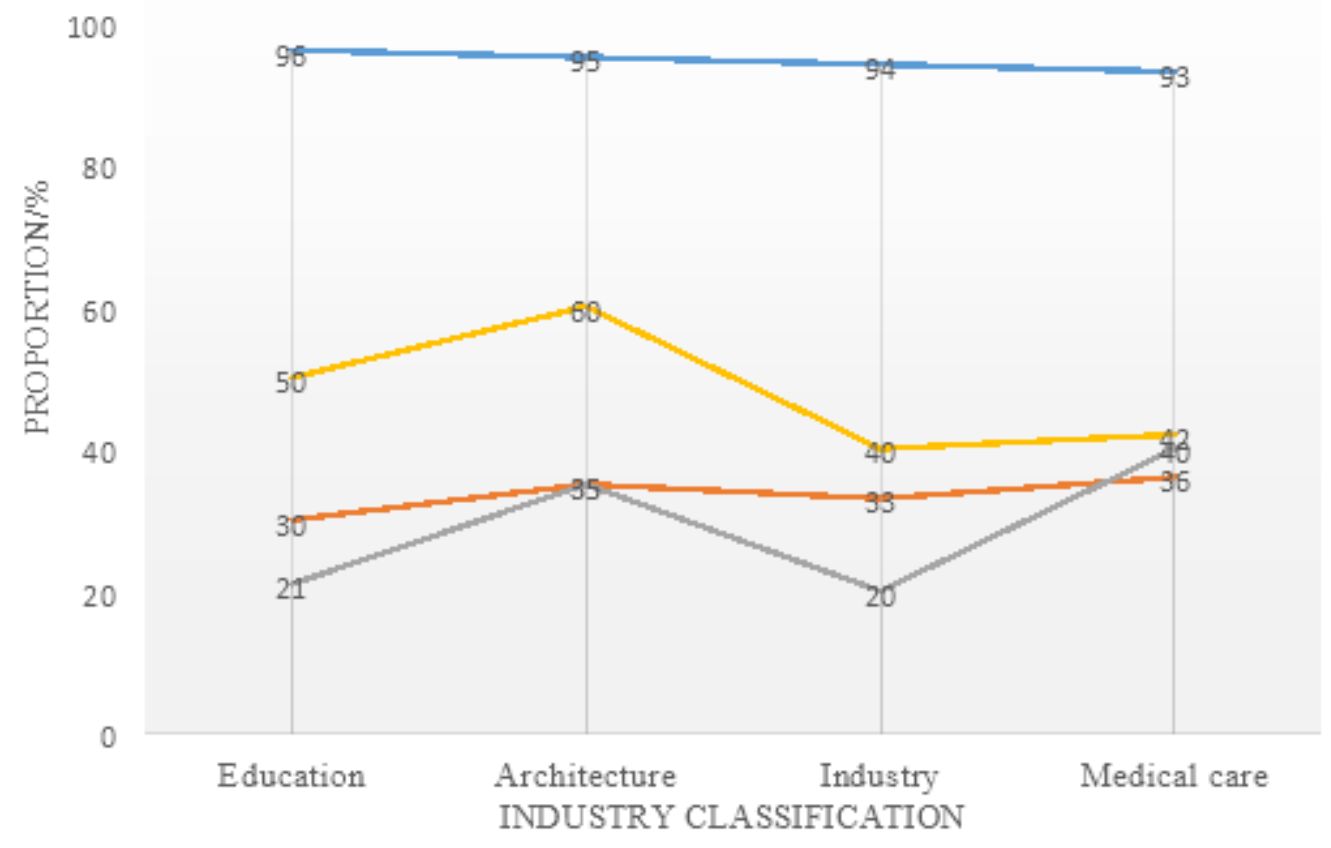

Figure 8

Use of emerging technologies in various fields 


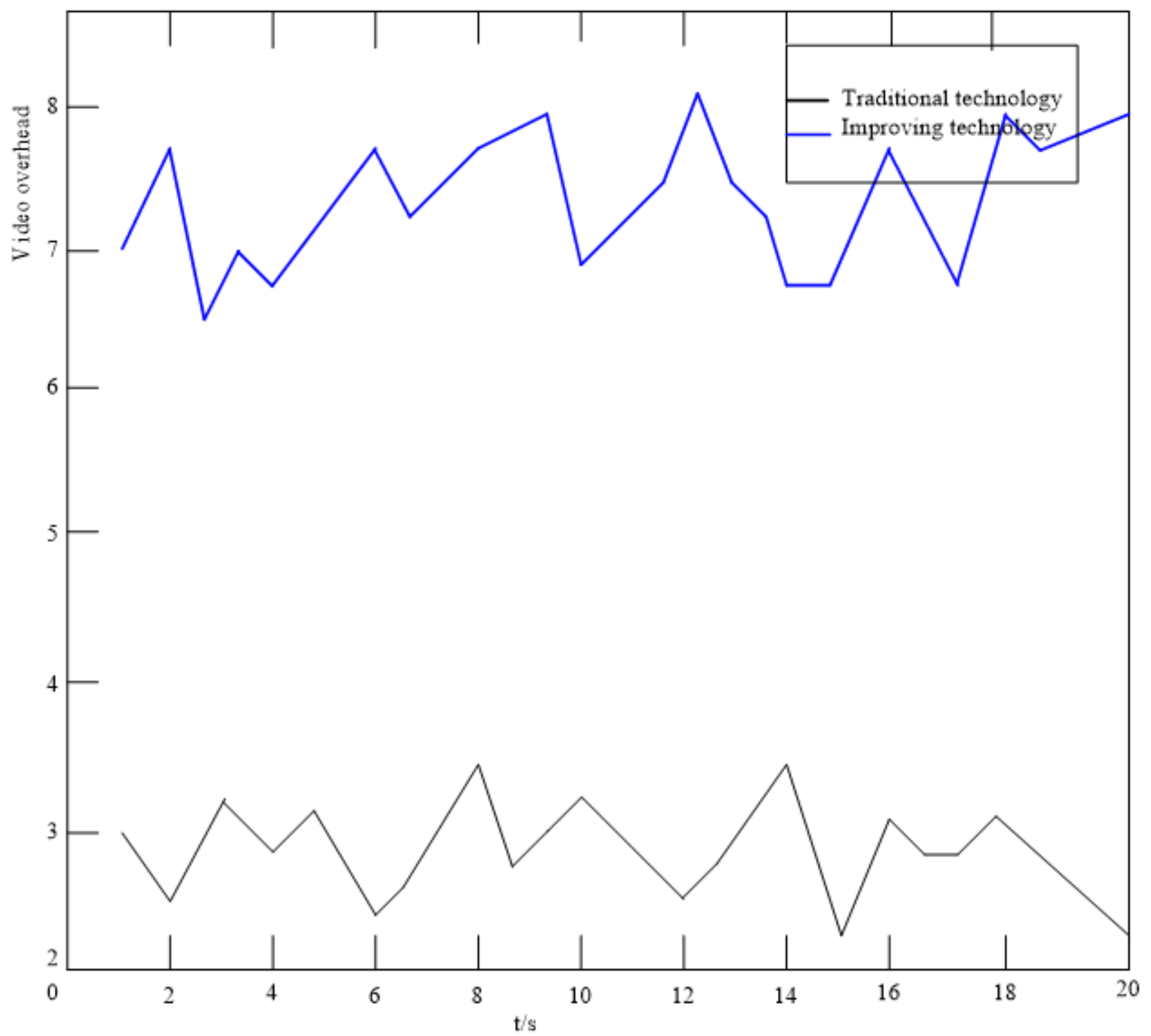

Figure 9

Contrast diagram of video transmission quality 